\title{
Recurrence of Human Babesiosis Caused by Reinfection
}

\author{
Jonathan Ho, ${ }^{1}$ Erin Carey, Dennis E. Carey, Peter J. Krause
}

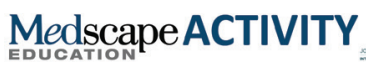

In support of improving patient care, this activity has been planned and implemented by Medscape, LLC and Emerging Infectious Diseases. Medscape, LLC is jointly accredited by the Accreditation Council for Continuing Medical Education (ACCME), the Accreditation Council for Pharmacy Education (ACPE), and the American Nurses Credentialing Center (ANCC), to provide continuing education for the healthcare team.

Medscape, LLC designates this Journal-based CME activity for a maximum of 1.00 AMA PRA Category 1 Credit(s) ${ }^{\mathrm{TM}}$. Physicians should claim only the credit commensurate with the extent of their participation in the activity.

Successful completion of this CME activity, which includes participation in the evaluation component, enables the participant to earn up to $1.0 \mathrm{MOC}$ points in the American Board of Internal Medicine's (ABIM) Maintenance of Certification (MOC) program. Participants will earn MOC points equivalent to the amount of CME credits claimed for the activity. It is the CME activity provider's responsibility to submit participant completion information to ACCME for the purpose of granting ABIM MOC credit.

All other clinicians completing this activity will be issued a certificate of participation. To participate in this journal CME activity: (1) review the learning objectives and author disclosures; (2) study the education content; (3) take the post-test with a $75 \%$ minimum passing score and complete the evaluation at http://www.medscape.org/journal/eid; and (4) view/print certificate. For CME questions, see page XXX.

Release date: September 17, 2021; Expiration date: September 17, 2022

\section{Learning Objectives}

Upon completion of this activity, participants will be able to:

- Describe clinical findings and course in a previously healthy patient who experienced a second episode of babesiosis 3 years

after an initial episode

- Determine laboratory findings in a previously healthy patient who experienced a second episode of babesiosis 3 years after an initial episode

- Identify clinical implications of a case of babesiosis in a previously healthy patient who experienced a second episode of babesiosis 3 years after an initial episode

\section{CME Editor}

Thomas J. Gryczan, MS, Technical Writer/Editor, Emerging Infectious Diseases. Disclosure: Thomas J. Gryczan, MS, has disclosed no relevant financial relationships.

\section{CME Author}

Laurie Barclay, MD, freelance writer and reviewer, Medscape, LLC. Disclosure: Laurie Barclay, MD, has disclosed no relevant financial relationships.

\section{Authors}

Disclosures: Jonathan Ho, MD; Erin E. Carey, MS; and Dennis E. Carey, MD, have disclosed no relevant financial relationships. Peter J. Krause, MD, has disclosed the following relevant financial relationships: received grants for clinical research from Gold Standard Diagnostics.

Author affiliations: Yale School of Public Health, New Haven, Connecticut, USA (J. Ho, P.J. Krause); University of Bridgeport, Bridgeport, Connecticut, USA (E. Carey); Zucker School of Medicine at Hofstra/Northwell, Hempstead, New York, USA (D.E. Carey); Yale School of Medicine, New Haven (P.J. Krause) 
Babesiosis developed in a 62-year-old immunocompetent physician, who had an uneventful recovery after receiving atovaquone and azithromycin. Three years later, babesiosis developed again, and he was again successfully given treatment. Clinical and laboratory evidence were highly supportive of Babesia reinfection. Healthcare professionals should be aware that reinfection might occur in babesiosis.

$B$ abesia microti, the primary cause of human babesiosis, is an intraerythrocytic protozoan that is transmitted by hard-bodied ticks to mammalian hosts and occasionally to humans (1). White-footed mice are the primary host and once infected may remain so for life. Parasitemia also persists in humans, even after antimicrobial drug therapy (2-7). Immunocompetent human hosts can experience asymptomatic infection for as long as 1 year after antimicrobial drug therapy, although most patients clear infection within several months. Patients who are immunocompromised generally have a longer duration of infection and may experience relapsing symptoms. These patients might remain parasitemic for as long as 2 years, despite antimicrobial drug therapy $(5,7)$. Most patients recover without longterm complications, although babesiosis can result in fatal illness $(1,6)$.

We report a case of babesiosis in a previously healthy patient who experienced a second episode of babesiosis 3 years after an initial episode. He was given a standard course of antimicrobial drugs for $\mathrm{Ba}$ besia infection for each episode.

\section{The Study}

A 62-year-old physician living in Huntington, Long Island, New York, USA, was in good health until June 9, 2013, when he felt unwell and fever, chills, headache, myalgias, fatigue, sweats, joint pain, poor appetite, and conjunctivitis developed. On the third day of illness, he noted dark urine that lasted for several days. On June 13, he was seen by his family physician, who noted fever but no other abnormality.

A complete blood count (CBC) showed a hemoglobin level of $13.9 \mathrm{~g} / \mathrm{dL}$ (reference range $13 \mathrm{~g} / \mathrm{dL}-18$ $\mathrm{g} / \mathrm{dL})$; a hematocrit of $40.8 \%(40 \%-54 \%)$; a leukocyte count of 4,700 cells $/ \mu \mathrm{L}(4,500$ cells $/ \mu \mathrm{L}-11,000$ cells/ $\mu \mathrm{L})$ with $55 \%$ neutrophils $(54 \%-62 \%)$ and $28 \%$ lymphocytes $(25 \%-33 \%)$; a platelet count of 68,000 cells/ $\mu \mathrm{L}(150,000$ cells $/ \mu \mathrm{L}-400,00$ cells $/ \mu \mathrm{L})$; an aspartate aminotransferase level of $65 \mathrm{U} / \mathrm{L}(1 \mathrm{U} / \mathrm{L}-36 \mathrm{U} / \mathrm{L})$; and an alanine aminotransferase level of ALT $70 \mathrm{U} / \mathrm{L}$ (1 U/L-45 U/L). He was told to return for reevaluation if symptoms did not resolve and was seen again on June 16. At that time, he had a fever (temperature $\left.103^{\circ} \mathrm{F}\right)$. He was given doxycycline (100 mg orally every $12 \mathrm{~h}$ ) but did not improve.

Laboratory results on June 16 showed that a $B$. microti IgM result was strongly positive (IgM titer $\geq 1: 1,024$, IgG titer $\leq 1: 16$ ), but Anaplasma phagocytophilum antibody was absent (Table). He was then given atovaquone (750 mg, $2 \times / \mathrm{d}$ for $2 \mathrm{wks}$ ) and azithromycin $(500 \mathrm{mg}, 1 \times / \mathrm{d}$ for $2 \mathrm{wks})$. He recovered completely 3 weeks after symptoms began.

Subsequent attempts to perform Babesia wholegenome sequencing on a residual blood sample obtained 3 days after the start of treatment identified $B$. microti DNA, but it was insufficient to perform fullgenomic sequencing. At a follow-up visit to his physician on July 5, a CBC and tests for aspartate and alanine aminotransferase levels showed results within references ranges.

Three years later, on June 19, 2016, the patient had fever (temperature $100^{\circ} \mathrm{F}$ ), chills, sweats, headache, myalgias, anorexia, and difficulty concentrating develop. He also noted dark urine for several days. On June 22 , he was seen by his physician, who obtained a CBC, which showed a hemoglobin level of $12.6 \mathrm{~g} / \mathrm{dL}$ and hematocrit of $38.3 \%$; a leukocyte count of 4,700 cells/ $\mu \mathrm{L}$ with $55 \%$ neutrophils and $30 \%$ lymphocytes; and a platelet count of 41,000 cells $/ \mu \mathrm{L}$. A blood smear showed a Babesia parasitemia level of $1 \%$. We amplified B. microti DNA by using PCR. Results for $B$. microti antibody were positive (IgM titer 1:256, IgG titer $\geq 1 ; 1,024)$ (Table). He was then given atovaquone (750 mg every $12 \mathrm{~h}$ ) and azithromycin (500 mg on day 1 and then $250 \mathrm{mg} 1 \times / \mathrm{d}$ ) for 10 days, at which time symptoms had resolved. A repeat blood smear did not show any parasites. The patient has subsequently been in good health.

\section{Conclusions}

This patient had 2 separate episodes of B. microti babesiosis 3 years apart. He lived in an area where B. microti was hyperendemic and showed typical symptoms of Babesia infection during each episode, including dark urine that is indicative of hemoglobinuria (8). In the first episode, he did not have a blood smear or PCR performed, but a high B. microti IgM response was suggestive of $B$. microti infection $(1,9)$. B. microti infection was subsequently confirmed by identification of $B$. microti DNA. In the second episode, B. microti infection was confirmed by blood smear and PCR.

Both clinical and laboratory evidence support reinfection rather than relapse of infection for this patient. He was repeatedly exposed to ticks in an area 
Table. Babesia microti indirect fluorescent antibody test results for patient who had babesiosis 2 times, New York, USA

\begin{tabular}{lccc}
\hline B. microti test date & Days after onset of symptoms & B. microti IgM titer & B. microti lgG titer \\
\hline Episode 1, 2013 Jun 16 & 7 & $\geq 1: 1,024$ & $<1: 16$ \\
Episode 2, 2016 Jun 22 & 4 & $1: 256$ & $\geq 1: 1,024$ \\
\hline
\end{tabular}

where babesiosis is commonly reported (1). He was in good general health without evidence of immunosuppression, whereas all cases of relapsing babesiosis have been reported in immunocompromised persons. After the first episode of babesiosis, he had complete clinical recovery 2 weeks after the onset of infection and did not experience the second episode until 3 years later. In contrast, those persons who have had relapsed $B$. microti infection have all been immunocompromised, experienced relapses of infection 2 weeks to 3 months after the previous episode, and usually lack full clinical recovery between relapses (3-7). Finally, our patient had a robust B. microti IgM response 2 weeks after the onset of his first infection and an anamnestic antibody response with a high $\operatorname{IgG}$ titer on day 4 of the second infection, which is characteristic of reinfection rather than relapse. Patients who have experienced relapse have conditions that impair antibody response (e.g., B cell lymphoma, rituximab therapy, HIV/AIDS). A minimal or absent B. microti antibody response has been demonstrated in patients who have had relapsing babesiosis and have been tested for B. microti antibody $(5,7)$.

Previous studies describe the persistence of human B. microti infection and clinical immunity. In a prospective study of babesiosis patients who were tested for B. microti DNA by PCR every 3 months after acute illness until infection cleared, parasitemia persisted up to 13 months in 22 antimicrobial drugtreated patients and up to 27 months in 23 untreated patients (2). In another study, a patient was reported as having relapsing infection that persisted for 27 months (5). The immediate host response to B. microti infection is provided by innate immune elements that include the spleen, macrophages, and neutrophils. In contrast, long-term clearance of $B$. microti parasites depends in large part on antibody (2-7). Studies of the duration of $B$. microti antibody have demonstrated persistence for as little as 6 months and as long as 6 years $(2,6,10-11)$.

Although there is strong evidence that our patient experienced reinfection, we do not have absolute confirmation, and it is possible that he could have had persistent $B$. microti infection that relapsed after 3 years. No B. microti PCR (or blood smear) was obtained after the initial infection. We attempted to further distinguish between relapse and reinfection by genetic sequencing of $B$. microti DNA from blood samples obtained from both episodes of infection. Unfortunately, we were unable to obtain sufficient DNA from the first episode for sequencing because a blood sample was only available 3 days after antimicrobial drug therapy was initiated, leaving few viable parasites.

In summary, our study shows evidence of reinfection after successful treatment of a B. microti infection. Although the evidence is highly supportive, it is not definitive. Whether our patient experienced reinfection or relapse 3 years after the initial infection, investigation of similar patients could provide useful information about the immune response to $B$. microt $i$ infection. Patients who have experienced babesiosis, and their healthcare professionals, need to be aware that babesiosis reinfection might occur, as for Lyme disease $(12,13)$. Tickborne disease preventive measures should be maintained for patients with or without a history of babesiosis (14).

This study was supported in part by the Gordon and Llura Gund Foundation.

\section{About the Author}

Dr. Ho is a resident of internal medicine at Rhode Island Hospital/Warren Alpert Medical School, Brown University, Providence, RI. His research interests include antimicrobial drug resistance and quality care in gastroenterology.

\section{References}

1. Vannier E, Krause PJ. Human babesiosis. N Engl J Med. 2012;366:2397-407. https:/ / doi.org/10.1056/NEJMra1202018

2. Krause PJ, Spielman A, Telford SR III, Sikand VK, McKay K, Christianson D, et al. Persistent parasitemia after acute babesiosis. N Engl J Med. 1998;339:160-5. https://doi.org/10.1056/NEJM199807163390304

3. Lemieux JE, Tran AD, Freimark L, Schaffner SF, Goethert H, Andersen KG, et al. A global map of genetic diversity in Babesia microti reveals strong population structure and identifies variants associated with clinical relapse. Nat Microbiol. 2016;1:16079. https://doi.org/10.1038/ nmicrobiol.2016.79

4. Simon MS, Westblade LF, Dziedziech A, Visone JE, Furman RR, Jenkins SG, et al. Clinical and molecular evidence of atovaquone and azithromycin resistance in relapsed Babesia microti infection associated with rituximab and chronic lymphocytic leukemia. Clin Infect Dis. 2017;65:1222-5. https://doi.org/10.1093/cid/cix477

5. Raffalli J, Wormser GP. Persistence of babesiosis for $>2$ years in a patient on rituximab for rheumatoid arthritis. Diagn 
Microbiol Infect Dis. 2016;85:231-2. https:/ / doi.org/ 10.1016/j.diagmicrobio.2016.02.016

6. Bloch EM, Kumar S, Krause PJ. Persistence of Babesia microti infection in humans. Pathogens. 2019;8:102. https:/ / doi. org/10.3390/pathogens8030102

7. Krause PJ, Gewurz BE, Hill D, Marty FM, Vannier E, Foppa IM, et al. Persistent and relapsing babesiosis in immunocompromised patients. Clin Infect Dis. 2008;46:370-6. https:/ / doi.org/10.1086/525852

8. Hunfeld KP, Hildebrandt A, Gray JS. Babesiosis: recent insights into an ancient disease. Int J Parasitol. 2008;38:1219-37. https://doi.org/10.1016/j.ijpara.2008.03.001

9. Krause PJ, Ryan R, Telford S III, Persing D, Spielman A. Efficacy of immunoglobulin M serodiagnostic test for rapid diagnosis of acute babesiosis. J Clin Microbiol. 1996;34:20146. https://doi.org/10.1128/jcm.34.8.2014-2016.1996

10. Ruebush TK II, Chisholm ES, Sulzer AJ, Healy GR. Development and persistence of antibody in persons infected with Babesia microti. Am J Trop Med Hyg. 1981;30:291-2. https:/ / doi.org/10.4269/ajtmh.1981.30.291
11. Moritz ED, Winton CS, Tonnetti L, Townsend RL, Berardi $\mathrm{VP}$, Hewins ME, et al. Screening for Babesia microti in the U.S. blood supply. N Engl J Med. 2016;375:2236-45. https://doi.org/10.1056/NEJMoa1600897

12. Nadelman RB, Hanincová $K$, Mukherjee $P$, Liveris D, Nowakowski J, McKenna D, et al. Differentiation of reinfection from relapse in recurrent Lyme disease. N Engl J Med. 2012;367:1883-90. https:/ / doi.org/10.1056/ NEJMoa1114362

13. Krause PJ, Foley DT, Burke GS, Christianson D, Closter L, Spielman A; Tick-Borne Disease Study Group. Reinfection and relapse in early Lyme disease. Am J Trop Med Hyg. 2006;75:1090-4. https://doi.org/10.4269/ajtmh.2006.75.1090

14. Piesman J, Beard CB. Prevention of tick-borne diseases. J Environ Health. 2012;74:30-2.

Address for correspondence: Peter J. Krause, Yale University, 60 College St, New Haven, CT 06510; USA; email: peter.krause@yale.edu 